\title{
HELLP Syndrome- Maternal and Perinatal Outcome in a Tertiary Care Institution
}

\author{
Jisha Ismail ${ }^{1}$, Shaheera H. Thayat ${ }^{2}$ \\ ${ }^{1}$ Department of Obstetrics and Gynaecology, Government Medical College, Thrissur, Kerala, India. \\ 2Department of Obstetrics and Gynaecology, Government Medical College, Thrissur, Kerala, India.
}

\section{ABSTRACT}

\section{BACKGROUND}

HELLP syndrome characterized by haemolysis, elevated liver enzymes and low platelet count is an acronym coined by Dr Louis Weinstein in 19821. It occurs in about $0.5-0.9 \%$ of all pregnancies and in $10-20 \%$ cases with severe preeclampsia. HELLP syndrome is associated with substantial risk for the mother and foetus. There is always a controversy regarding the definition, diagnosis, cause and management of this enigmatic disease.

\section{METHODS}

This was a retrospective study conducted in the Department of O\&G, Government Medical College, Thrissur, Kerala. Women with more than 24 weeks of gestational age diagnosed as HELLP Syndrome by abnormal laboratory parameters, during the study period were analyzed for their demographic variables, clinical presentation and obstetric and perinatal outcome.

\section{RESULTS}

Of the 55 patients in the study, $24 \%$ had some complications. Postpartum haemorrhage was the most common complication followed by DIC. Caesarean hysterectomy was done in one case following severe atonic PPH. There was one case of maternal death, who developed DIC and acute renal failure. $89.1 \%$ of the babies were complicated by intrauterine growth restriction and $78.2 \%$ were preterm.

\section{CONCLUSIONS}

HELLP syndrome is an alarming diagnosis which has high maternal and perinatal morbidity and mortality. Outcome of HELLP syndrome depends on its severity, timely intervention, availability of blood and blood products and tertiary care hospital facilities. In spite of recent advances in our health care system, more efforts and further skilled care are required for satisfactory decline in adverse maternal and foetal outcome.

\section{KEY WORDS}

HELLP Syndrome, Haemolysis, Elevated Liver Enzymes, Thrombocytopaenia
Corresponding Author: Dr. Jisha Ismail. Department of Obstetrics and Gynaecology, Government Medical College,

Thrissur, Kerala, India.

E-mail: jishajameel@gmail.com

DOI: $10.14260 / j e m d s / 2019 / 705$

Financial or Other Competing Interests: None.

How to Cite This Article:

Ismail J, Thayat SH. HELLP syndromematernal and perinatal outcome in a tertiary care institution. J. Evolution Med. Dent. Sci. 2019;8(43):3253-3257, DOI: 10.14260/jemds/2019/705

Submission 28-08-2019,

Peer Review 09-10-2019,

Acceptance 15-10-2019,

Published 28-10-2019. 


\section{BACKGROUND}

HELLP syndrome characterized by haemolysis, elevated liver enzymes and low platelet count is an acronym coined by $\mathrm{Dr}$ Louis Weinstein in $1982 .{ }^{1}$ It occurs in about $0.5-0.9 \%$ of all pregnancies and in 10-20\% cases with severe pre-eclampsia. ${ }^{2}$ It develops during antepartum period in $70 \%$ cases with the peak frequency between 27 to 37 weeks. Postpartum HELLP develops within the first 48 hours after delivery. Hypertension and proteinuria may be absent in $10-20 \%$ cases of HELLP syndrome. It is more common in multiparous and older pregnant women, but can occur with any parity and age. Clinical symptoms include upper abdominal pain, nausea and vomiting, malaise, headache, oedema, weight gain, hypertension and proteinuria. Jaundice is seen only in $5 \%$ of patients.

Haemolysis occurs as a result of microangiopathic haemolytic anaemia due to generalized endothelial and microvascular injury. Diagnosis of haemolysis is supported by high LDH concentration, the presence of unconjugated bilirubin and low or undetectable haptoglobin levels. It is classified according to criteria developed by University of Mississippi 2006,3 based on platelet count, class 1 stands for platelet count less than $50000 / \mu \mathrm{L}$, class 2 for less than 100 $000 / \mu \mathrm{L}$ and class 3 for a count less than $150000 / \mu \mathrm{L}$. The Tennessee classification ${ }^{4}$ defines the characteristics of the disease as the presence of haemolysis, with total serum lactic dehydrogenase greater than or equal to $600 \mathrm{IU} / \mathrm{L}$, serum aminotransferases greater than or equal to $70 \mathrm{IU} / \mathrm{L}$ and platelets less than or equal to $100000 / \mu \mathrm{L}$.

The diagnosis of complete HELLP syndrome requires all three major components of the triad while partial HELLP syndrome requires only 1 or 2 elements of the triad. The incidence of partial HELLP syndrome is unclear, probably around 21 to $24 \% 5$. The HELLP syndrome is associated with substantial risk for the mother and foetus. The common complications seen are renal failure, abruptio placenta, consumptive coagulopathy, pulmonary oedema, sub capsular liver haematoma and hypovolemic shock. The main strategy of management of HELLP syndrome is its early diagnosis, and timely interventions to minimize the complications. There is always a controversy regarding the definition, diagnosis, cause and management of this enigmatic disease. The aim of the present study is to identify the clinical issues of the syndrome with special focus on diagnosis, complication, perinatal morbidity and mortality.

\section{METHODS}

This was a retrospective study is conducted in the Department of O\&G, Government Medical College, Thrissur, Kerala. The case records of patients with more than 24 weeks of gestational age, diagnosed with HELLP syndrome according to the standard diagnostic criteria ${ }^{3,4}$ managed in our hospital during the period from January 2015 to December 2017 were reviewed. Conditions which mimic HELLP syndrome like acute fatty liver of pregnancy, Thrombotic thrombocytopenic purpura, Haemolytic uraemic syndrome, idiopathic thrombocytopenia, Infections/inflammatory disease not specifically related to pregnancy were excluded from the study. Institutional approval for the study and its proforma were obtained following standard institutional research committee procedures. The incidence of HELLP syndrome and the demographic variables of the patients were noted. HELLP was classified to complete or partial and was graded according to Mississippi classification 4 . The gestational age at onset of Hypertension and HELLP Syndrome were noted. The clinical presentation of the patients, their obstetric outcome and the mode of delivery were noted. The need of blood and blood products, the complications and the duration of hospital stay were studied. The immediate perinatal outcome in terms of intrauterine growth restriction (IUGR), intrauterine death (IUD), Neonatal death (NND), preterm births, and duration of NICU stay were also noted.

\section{Statistical Analysis}

The data was analysed by Microsoft Office Excel 2010 version. The results were expressed as number and percentage for all the qualitative variables and frequency table were created. Mean and standard deviation were used for quantitative variables.

\section{RESULTS}

Out of 10565 pregnant women there were 852 cases of hypertension complicating pregnancy, of which 55 cases developed HELLP syndrome, which had $0.5 \%$ incidence and $6.4 \%$ in preeclampsia.

\begin{tabular}{|c|c|c|}
\hline Age (Years) & Number & Percentage \\
\hline$<20$ & 5 & 9.1 \\
\hline $20-24$ & 12 & 21.8 \\
\hline $25-29$ & 25 & 45.5 \\
\hline $30-34$ & 6 & 10.9 \\
\hline$\geq 35$ & 7 & 12.7 \\
\hline Socioeconomic status & Number & Percentage \\
\hline BPL & 33 & 60 \\
\hline APL & 17 & 30.9 \\
\hline Tribal & 5 & 9.1 \\
\hline Occupation & Number & Percentage \\
\hline Housewife & 40 & 72.7 \\
\hline Labourer & 10 & 18.2 \\
\hline Skilled labourer & 5 & 9.1 \\
\hline Place of residence & Number & Percentage \\
\hline Rural & 46 & 83.6 \\
\hline Urban & 9 & 16.4 \\
\hline \multicolumn{2}{|c|}{ Table 1. Sociodemographic Profile } \\
\hline
\end{tabular}

Majority of cases were between 25-29 years (45.5\%). Most of the patients belonged to low socioeconomic status and were from rural areas.

\begin{tabular}{|c|c|c|}
\hline Parity & Number & Percentage \\
\hline primi & 24 & 43.6 \\
\hline Para 1 & 19 & 34.5 \\
\hline Para 2 & 9 & 16.4 \\
\hline Para 3 and above & 3 & 5.5 \\
\hline \multicolumn{3}{|c|}{ Table 2. Obstetric Profile } \\
\hline
\end{tabular}

Majority of the patients were multigravidas. Interval between onset of HELLP syndrome and hypertension was less than one week in majority of the cases. 


\begin{tabular}{|c|c|c|}
\hline HELLP & Number & $\mathbf{\%}$ \\
\hline Complete HELLP & 34 & 61.8 \\
\hline Partial HELLP & 21 & 38.2 \\
\hline \multicolumn{2}{|c|}{} \\
\hline Partial HELLP & Number & $\%$ \\
\hline Haemolysis + Low platelet & 4 & 19.0 \\
\hline Haemolysis + Elevated liver enzyme & 7 & 33.3 \\
\hline Low platelet, Elevated liver enzyme & 10 & 47.6 \\
\hline \multicolumn{2}{|c|}{ Table 3. Clinical Presentation } \\
\hline
\end{tabular}

There were 34 cases of complete HELLP syndrome and 21 cases of partial HELLP syndrome during study period. Out of the cases of complete HELLP syndrome there were 4 cases of class 1,29 cases of class 2 and 3 cases of class 3. Majority of the cases belonged to class $2(85.2 \%)$.

\begin{tabular}{|c|c|c|}
\hline Clinical Presentation & Number & $\mathbf{\%}$ \\
\hline Severe PE + abnormal lab findings & 21 & 38.2 \\
\hline Epigastric pain & 11 & 20 \\
\hline Nausea, vomiting & 8 & 14.5 \\
\hline dyspnoea & 1 & 1.8 \\
\hline Yellowish discoloration of urine & 1 & 1.8 \\
\hline Facial puffiness & 1 & 1.8 \\
\hline Referred as HELLP & 6 & 10.9 \\
\hline Referred as partial HELLP & 4 & 7.3 \\
\hline Headache & 2 & 3.6 \\
\hline \multicolumn{2}{|c|}{ Table 4. Clinical Presentation } \\
\hline
\end{tabular}

Most of the patients (38.2\%) were referred from peripheral centres as case of severe preeclampsia with abnormal laboratory findings. Other clinical presentations were epigastric pain in $11(20 \%)$, nausea vomiting in $8(14.5 \%)$, headache in $2(3.6 \%) .1$ patient presented with dyspnoea, 1 with yellowish discoloration of urine and another one with facial puffiness (1.8\%).

\begin{tabular}{|c|c|c|}
\hline Mode of Delivery & Vaginal & CS \\
\hline Number (\%) & $21(38.2)$ & $34(61.8)$ \\
\hline Indication for CS & & Number \\
\hline Elderly primi & 1 & 2.9 \\
\hline Previous CS & 13 & 38.2 \\
\hline IUGR, Abnormal doppler & 2 & 5.9 \\
\hline Type 4 placenta previa & 1 & 2.9 \\
\hline Grade 2 abruption & 1 & 2.9 \\
\hline Fetal distress & 6 & 17.6 \\
\hline failed induction & 8 & 23.5 \\
\hline Maternal distress & 1 & 2.9 \\
\hline DIC & 1 & 2.9 \\
\hline \multicolumn{2}{|c|}{ Table 5. Maternal and Fetal Outcome } \\
\hline
\end{tabular}

Majority of the patients (64.82\%) underwent caesarean section. Previous caesarean section was the most common indication $(38.2 \%)$ for caesarean section.

\begin{tabular}{|c|c|c|}
\hline Maternal Morbidity & Number & $\mathbf{\%}$ \\
\hline Abruption & 3 & 5.5 \\
\hline MODS & 1 & 1.8 \\
\hline Acute renal failure & 3 & 5.5 \\
\hline Atonic PPH & 7 & 12.7 \\
\hline Cerebral oedema & 1 & 1.8 \\
\hline DIC & 4 & 7.3 \\
\hline Wound infection & 1 & 1.8 \\
\hline Wound hematoma & 1 & 1.8 \\
\hline pulmonary oedema & 2 & 3.6 \\
\hline Hepatic infarction & 1 & 1.8 \\
\hline Fetal complications & Number & \% \\
\hline IUGR & 49 & 89.1 \\
\hline Preterm & 43 & 78.2 \\
\hline NND & 3 & 5.45 \\
\hline NICU admission & 31 & 56.4 \\
\hline IUD & 12 & 21.8 \\
\hline \multicolumn{2}{|c|}{}
\end{tabular}

Of the 55 patients in the study 24 (43.6\%) had some complications. Postpartum haemorrhage was the most common complication followed by DIC. Caesarean hysterectomy was done in one case following severe atonic PPH. There was one case of maternal death, who developed DIC and acute renal failure. She was started on haemodialysis but died on post-operative day 17 due to sepsis and multiorgan dysfunction. $89.1 \%$ of the babies were complicated by intrauterine growth restriction and $78.2 \%$ were preterm.

\section{DISCUSSION}

HELLP syndrome is a major contributor of maternal and perinatal morbidity and mortality. The incidence of HELLP Syndrome in preeclampsia in the present study is $6.4 \%$ which is comparable, to the study of Ara $\mathrm{S}$ et al $5(6.5 \%)$. A study done by Sibai B M et al ${ }^{6}$ in 1985 reported an incidence of HELLP as 9.7\%. Lakshmi et $\mathrm{al}^{7}$ in a study published in 2007 reports an incidence of $14.7 \%$. Campos et $\mathrm{al}^{8}$ reports a prevalence of HELLP syndrome as $28 \%$ among all cases of severe preeclampsia and of $0.2 \%$ among all deliveries.

Our study showed that the incidence is slightly higher in multigravida compared to primi which is comparable to the study by Sowjanya et al. ${ }^{9}$ Aswini et al ${ }^{10}$ and Lakshmi et al ${ }^{7}$ reported the increased incidence of HELLP syndrome in Primi in their studies, $58 \%$ and $73.3 \%$ respectively. Chawla et al ${ }^{11}$ reported in his study that the condition was equally distributed in primi and multigravida.

Only $20 \%$ of the patients had hypertension in their previous pregnancies. All 55 cases (100\%) were antepartum which is similar to Lakshmi et al ${ }^{7}$ study but comparatively higher than in of Ara S et $\left.\mathrm{al}^{6} 75 \%\right)$ and Soujanya et $\mathrm{al}^{9}(84.2 \%)$. Several studies report that postpartum HELLP is more likely to be complete than partial and could be more dangerous than antepartum HELLP. Mean systolic and diastolic BP was $154.95 \pm 27.77$ and $99.64 \pm 15.13$ respectively. $10(18.2 \%)$ of patients had a diastolic BP <90 and $16(29 \%)$ had DBP $>110$ mmHg.

Majority had onset of the disease between 32 to 36 weeks which is similar to the study by Lakshmi et al. ${ }^{7}$ Most of the patients didn't have any specific presenting symptoms and were referred from peripheral hospitals in view of severe preeclampsia. Sibai et al in his study reported that $90 \%$ of the patients presented with epigastric and $\backslash$ or right upper quadrant pain, the next common symptom was headache followed by vomiting. Our experience shows that careful monitoring of hypertension and laboratory parameters is important in identifying this condition as majority were asymptomatic in our study.

HELLP syndrome can mimic many medical and surgical conditions, some of which are associated with high maternal mortality, whose therapies are quite different and may cause long term sequelae. This can mislead the diagnosis and hence utmost vigilance is needed in diagnosing this condition. The severity of HELLP syndrome correlates with the elevation of liver enzymes and thrombocytopenia. Campos et $\mathrm{al}^{8}$ in his study found that thrombocytopenia $<100000 / \mu \mathrm{L}$ and lactate dehydrogenase more than $1000 \mathrm{IU} / \mathrm{L}$ were the significant risk factors for this syndrome. A study by Aswini et $\mathrm{al}^{10}$ reports that there was three fold elevations in liver enzymes and the 
platelet count was half of the normal value in majority of the patients. Our study shows that the severity of HELLP syndrome is reflected in its laboratory parameters, and not in the usual clinical parameters like blood pressure that typically reflect preeclampsia disease severity.

$64.8 \%$ of patients underwent caesarean delivery. Caesarean section rate is low when compared to the study by Lakshmi et $\mathrm{al}^{7}$ (86.6\%) but when compared to other studies, the patients who underwent caesarean delivery was higher. In the study by Sowjanya et al $^{9} 71.5 \%$ had vaginal delivery. The increased rate of caesarean when compared to vaginal delivery in our study is due to the fact that $38.2 \%$ of patients had a previous caesarean section, and hence underwent a repeat section. There is definitely increased maternal morbidity in doing a caesarean section in patients with HELLP syndrome, but in those cases in which imminent delivery is not possible, an operative delivery may have to be resorted to prevent end stage complications and irreversible damage.

The maternal morbidity in this study was $40 \%$ which shows the significance of the condition. $10.9 \%$ had atonic PPH, which was controlled by medical management and condom tamponade and one case managed surgically. 5.5\% had abruptio placentae and $7.3 \%$ were complicated with DIC. Sibai et ${ }^{12} \mathrm{al}$ in his retrospective cohort study reports that, 38\% of pregnant women with the HELLP syndrome developed DIC (PLTs $<100 \cdot 10^{9} / \mathrm{L}$, low serum fibrinogen concentration $(<3$ $\mathrm{g} / \mathrm{L})$, fibrin degradation products (FDP) $(>40 \mu \mathrm{g} / \mathrm{ml}=40$ $\mathrm{mg} / \mathrm{L}$ ) most often related to placental abruption. Study by Lakshmi et al reported a maternal morbidity of $60 \%$, of which the major complications were DIC and renal failure, and maternal mortality was $6.7 \%$. Our study had a maternal mortality of $1.8 \%$ which is comparable to the study by Sibai et $\mathrm{al}^{13}$ which is in accordance with other studies by Audibert et $\mathrm{al}^{14}$ and Martin et al. ${ }^{15}$

HELLP syndrome is a condition which has high perinatal morbidity and mortality which is related to gestational age of the onset of the clinical situation. According to Gul et al ${ }^{16}$ the perinatal mortality was $34 \%$ before 32 weeks' gestation, and $8 \%$ after the $32 \mathrm{nd}$ gestational week. Lakshmi et al in his study reported a perinatal mortality of $46.6 \%$. Our study had a perinatal morbidity of $56.45 \%$ and perinatal mortality of $27.3 \%$. Of the 15 cases of perinatal death, 12 were intrauterine deaths and 3 were neonatal deaths. The high perinatal morbidity and mortality itself implies the significance of the condition.

The HELLP syndrome is rare but dreadful complication of pregnancy. Its presentation is variable leading to inappropriate management ending in increased maternal and perinatal mortality and morbidity. Devastating complications of HELLP syndrome in pregnancy could be prevented by regular antenatal check-up, timely prediction of risk factors, availability of better transport facilities and prompt referral. HELLP syndrome must be treated in a tertiary care centre. The global maternal mortality rate of HELLP syndrome is $25 \%$. In spite of recent advances in the public health and provision of our primary health care units much more efforts and further skilled care are mandatory for satisfactory decline in adverse maternal and foetal outcome.

\section{CONCLUSIONS}

The HELLP syndrome is rare but dreadful complication of pregnancy. Its presentation is variable leading to inappropriate management ending in increased maternal and perinatal mortality and morbidity. Devastating complications of HELLP syndrome in pregnancy could be prevented by regular antenatal check-up, timely prediction of risk factors, availability of better transport facilities and prompt referral. HELLP syndrome must be treated in a tertiary care centre. The global maternal mortality rate of HELLP syndrome is $25 \%$. In spite of recent advances in the public health and provision of our primary health care units, more efforts and further skilled care are required for satisfactory decline in adverse maternal and foetal outcome.

\section{REFERENCES}

[1] Weinstein L. HELLP Syndrome. Am J Obstet Gynecol 1982;9:95-111.

[2] Weinstein L. Syndrome of haemolysis, elevated liver enzymes and low platelet count: a severe consequence of hypertension in pregnancy. Am J Obstet Gynecol 1982;142(2):159-67.

[3] Martin JN Jr. Milestones in the quest for best management of patients with HELLP syndrome (microangiopathic hemolyticanemia, hepatic dysfunction, thrombocytopenia). Int J Gynecol Obstet 2013;121(3):202-7.

[4] Barton JR, Sibai BM. Diagnosis and management of haemolysis, elevated liver enzymes, and low platelets syndrome. Clin Perinatol 2004;31(4):807-33.

[5] Ara S, Singh BB, Birla N, et al. Incidence of HELLP Syndrome in pre-eclampsia and eclampsia and maternal and perinatal outcome including morbidity and mortality. Indian Journal of Research 2015;4(7):65-7.

[6] Sibai BM. The HELLP syndrome (hemolysis, elevated liver enzymes, and low platelets): much ado about nothing? Am J Obstet Gynecol 1990;162(2):311-6.

[7] Lakshmi NK, Kavitha G, Devi PK, et al. Study on HELLP syndrome - maternal and perinatal outcome. Int J Reprod Contracept Obstet Gynecol 2017;6:714-9.

[8] Campos A, Goncalves A, Massa AC, et al. HELLP Syndrome a severe form of preeclampsia: a comparative study of clinical and laboratorial parameters. American Journal of Experimental and Clinical Research 2016;3(3):170-4.

[9] Sowjanya K, Bhavani. Clinical study on HELLP Syndrome - maternal and perinatal outcome. IOSR Journal of Dental and Medical Sciences 2016;15(1):71-6.

[10] Mallesara A, Kanta SR, Shivappa P. A clinical study of HELLP syndrome and its outcome in a tertiary health care system. Int J Reprod Contracept Obstet Gynecol 2016;5(12):4196-9.

[11] Chawla S, Marwaha A, Raju A. HELLP or help: a real challenge. The Journal of Obstetrics and Gynaecology of India 2015;65(3):172-5. 
[12] Sibai BM, Taslimi MM, el-Nazer A, et al. Maternal and perinatal outcome associated with the syndrome of hemolysis, elevated liver enzymes and low platelets in severe preeclampsia-eclampsia. Am J Obstet Gynecol 1986;155(3):501-9.

[13] Sibai BM, Ramadan MK, Usta I, et al. Maternal morbidity and mortality in 442 pregnancies with hemolysis, elevated liver enzymes and low platelets (HELLP syndrome) Am J Obstet Gynecol 1993;169(4):1000-6.

[14] Audibert F, Friedman SA, Frangieh AY, et al. Clinical utility of strict diagnostic criteria for the HELLP (hemolysis, elevated liver enzymes and low platelets) syndrome. Am J Obstet Gynecol 1996;175(2):460-4.
[15] Martin JN Jr, Blake PG, Perry KG Jr, et al. The natural history of HELLP syndrome: patterns of disease progression and regression. Am J Obstet Gynecol 1991;164(6 Pt 1):1500-13.

[16] Gul A, Cebeci A, Aslan H, et al. Perinatal outcomes in severe preeclampsia-eclampsia with and without HELLP syndrome. Gynecol Obstet Invest 2005;59(2):113-8. 